\title{
ASSESSING BODY CULTURE LEVEL AND ITS ASSOCIATION WITH THE LEVEL OF PHYSICAL ACTIVITY IN UNIVERSITY STUDENTS
}

doi: 10.2478/v10038-012-0030-5

\section{BRUNO BARTH PINTO TUCUNDUVA}

Federal University of Paraná, Paraná, Brazil

\begin{abstract}
Purpose. Subjective values of physical activity are important for promoting active lifestyles. In theoretical research, body culture is the most appropriate term to analyze the complexity between exercise and human culture. The main goal of this study is to assess body culture level and to analyze its influence on physical activity levels. Methods. An online questionnaire containing the Exploratory Questionnaire of Body Culture Concepts, developed exclusively for this research, plus a short version of the International Physical Activity Questionnaire and a number of general identification questions were used to analyze body culture level. Results. 310 university students responded to the survey. A significant association between high body culture level and physical activity level was found. Conclusions. The assessment of body culture level helps to analyze the trends of physical activity. The role of cultural complexity of human movement should be considered as an important variable in the promotion of an active lifestyle.
\end{abstract}

Key words: physical education, body, culture, physical activity

\section{Introduction}

Exercise is commonly recognized as a means of promoting health and well being [1]. However, levels of physical inactivity are very high amongst populations of various societies around the world [2]. In Brazil in particular, several studies have indicated the prevalence of sedentary activities during the leisure time of the population [3]. These are two aspects of the same problem, which is the difficulty of promoting health through regular exercise. Even though the positive effects of physical activity are widely recognized, people still pursue an inactive lifestyle. Hence, any analysis of physical activity still requires the identification of key factors that would effectively encourage an individual to regularly and independently participate in exercise programs.

Through historical analysis, it has been shown that the first research into physical activity methods had a significant impact on the popular understanding of the organic benefits of exercise, creating a common acceptance of it as a tool for body development [4]. Although this is the (prime) popular concept of physical activity, it is still hegemonic in modern society.

Current research shows that physical activity has a broad potential for cultural development and education [5]. Thus, it is believed that through widespread recognition of physical activity as a cultural element for human growth, complementing the traditional meaning of exercise, can it be possible to achieve a greater legitimacy for such practices in a daily routine, facilitating the promotion of an active lifestyle.

Analyzing the cultural aspects of physical activity, the term body culture has been chosen as the most ap- propriate concept to show how one perceive's physical activity as an aspect of their own human experience.

The term body culture analyzes body practices as a way for the subject to perceive act and relate with the external environment in a social, expressive or functional way [6]. Thus, this study attempts to assess the subject's body culture level and analyze its level in relation to level of physical activity.

Body culture can be described as a proportion of general culture. It involves the symbolic and material significance of the practices of human motricity in a society [6]. Body culture in its noun form embraces the meanings and expressions of the body and its practices in human culture. As an adjective, body culture is the level of development of an individual's motricity in relation to their body consciousness, corporality and the recognition of the role of physical activity in the search for a healthy lifestyle [7].

The elements of body culture are described in games, sports, gymnastics, the practice of physical conditioning, rhythmic and expressive activities, dance and martial arts [7]. Its contents can be generalized as every human manifestation that links human spontaneous behavior to planned motor elements [6]. Hence, body culture contents extend from traditional sports to social activities, passing by other activities that involve a significant contingent of human motor function.

Nevertheless, body culture is an element of general culture, which implies that a great deal of complexity needs to be understood, especially in relation to the dialectic relation of man with nature [8]. Although man is an integral part of nature and has to respect the rhythm of evolution, he has the reflective capacity of 
transforming himself and the environment, which allows his elevation beyond nature's causality [9].

Culture is the connection of natural development with the intentional attribution of significant human meaning [9]. In terms of body culture, it is important to keep in mind that in physical activity there are natural elements, such as the physiological response of the body to the stimulus of exercise, as well as the perceived meaning of such activities for human growth.

Another important aspect is that the term culture has a strong meaning of identity for the individual [10]. Culture represents all that is specific to a given society and includes the development of social identity within cultural growth. The word culture integrates the historical development of a society including a society's traditions, beliefs, social and artistic developments and its technological and scientific advances. The single term encompasses the uniqueness of an individual in their society [10]. Similarly, body culture experiences are also an identity feature, since they bring a distinctive factor among individuals of a determined group, reflecting their development in the context of a society [11].

In light of such great complexity, a human's actions are described as "biocultural", where the organism is infiltrated by socio-cultural meanings [12]. Thus, body practices cannot be reduced to a physiological phenomenon, strictly as the displacement of the body in space and a set of muscular contractions, but must also be understood as an integrative activity of human expression in the wider world [13].

A diversity of intrinsic elements is developed by implementing a wide-ranging body culture [14]. Therefore, it is important that the subject comprehend that physical activity is an evolving element capable of an extensive cultural influence. This concept frames physical activity as something more than entertainment or a practice restricted to physical conditioning. Hence, the exploratory path of this research is directed to the assessment of the amplitude of perceived concepts linked to the term body culture in relation to the level of physical activity that individuals have in their daily routine.

\section{Material and methods}

The research took a quantitative approach with a transversal design, and was carried out by means of an online questionnaire with closed questions, broken down into three sections: the Exploratory Questionnaire of Body Culture Concepts (QBC) developed exclusively for this study; general identification; and the short version of the International Physical Activity Questionnaire (IPAQ) [15].

The first part of the questionnaire focused on the identification of each respondent's anthropometric variables, which provided the Body Mass Index (BMI), gender, age and the Socioeconomic Status (SES), measured according to the Brazilian Economic Classification
Criterion [16]. These were considered to be variables that could influence the statistical correlation between the levels of body culture and physical activity. However, the statistical procedures revealed no influence of these variables, in neither body culture nor physical activity level, as is detailed in this document.

The second part comprised of a short version of the International Physical Activity Questionnaire (IPAQ), which gave data on the amount of physical activity done in an individual's daily routine [15]. The subjects answered eight questions about the number of times and the duration of their physical activity, indicating low, moderate, and high intensity exercise done during the previous week.

The results were classified into categories of the individual's physical activity level (A, B, or C), according to the criteria established by the American College of Sports Medicine (ACSM) and its general requirements of physical activity for health promotion [17].

Physical activity level C (PAL C) consisted of people who were below the recommendations for health promotion. Physical activity level B (PAL B) consisted of subjects who performed the basic recommendation of 150 minutes of moderate intensity activity or 75 minutes of vigorously intensive activity per week. Physical activity level A (PAL A) consisted of subjects who reached a complementary indication of at least 300 minutes of moderate intensity physical activity or 150 minutes of vigorous intensity physical activity per week to attain additional health benefits.

The third part of the questionnaire was developed specifically for this study: the Exploratory Questionnaire of Body Culture Concepts (QBC). This instrument was based on the fundamentals of body culture, including areas such as human movement, body practices, and corporality.

The QBC consisted of 31 questions divided into 9 thematic sections that were related to values and concepts of physical activity and body culture in the subject's perspective. The answers fit into a Likert-type scale from 0 (null) to 4 (very high), which indicates the level of relevance given to the variable of each question [18]. The sections of the questionnaire were the following (See Appendix 1):

- Section 1 - Personal - 11 questions: psychological aspects related to motivation and the influence of physical activity on subjective values;

- Section 2 - Health - three questions: physical activity for the promotion of health;

- Section 3 - Social - two questions: physical activity and socialization;

- Section 4 - Body - three questions: emotions and sensations related to the practice of exercise;

- Section 5 - Practice - three questions: the dynamics of the practice of physical activity;

- Section 6-Cultural - three questions: the level of participation in public events related to sports 
and other bodily practices. Access and interest in media related to physical activity;

- Section 7 - History - one question/nine items: subjects' experiences with physical activities categorized within the concept of body culture;

- Section 8 - Spaces - one question/four items: utilization of different equipment and spaces for the practice of physical activity;

- Section 9 - Physical Activity Programs - four questions: participation and relevance of public physical activity programs and other important characteristics of these activities.

The QBC determined the body culture level (BCL) of the subjects by adding the responses in sections 1 to 9 . The results were divided into tertiles according to the scores achieved by the subject, specifying three BCL levels. Such division is necessary due to the dispersion of the results across the scale.

Low Body Culture Level ranges from 0 to 96 points and comprised 102 subjects. Medium Body Culture Level ranges from 97 to 119 points and comprised 105 subjects. High Body Culture Level ranges from 120 to 166 points and comprised 103 subjects.

A pilot study to verify the reproducibility and reliability of the QBC was conducted with fifty volunteers who did not participate in the final sample, but answered the questionnaire twice in a two week interval.

The results of this stage were tested with an intraclass correlation and a paired $t$-test. All tests were performed with Statistical Package for Social Sciences, version 11 (IBM, USA). The result of the first measurement showed an average of $64.3 \pm 6.8$ points in the overall responses and a median of 64.5 points. The result of the second measurement showed an average of $64.4 \pm$ 7.1 points in the overall responses and a median of 66 points. The significance level was fixed at $0.05(p \leq 0,05)$ and statistical analysis confirmed the reproducibility with an intra-class coefficient of 0.85 (95\% CI (0.65 to 0.94) $p \leq 0.001)$ and a $t$-test result of -0.06 and $p=0.9543$. In the final result of the questionnaire, the body culture level was proved to be reliable.

This study was approved by the Research Ethics Committee of Universidade Federal do Paraná, under the report $\mathrm{n}^{\mathrm{o}}$ 1032.157.10.10 and complied with resolution $n^{\circ} 196 / 96$ of the Brazilian National Health Council [19].

The participants consisted of 310 university students enrolled at the Universidade Tecnológica Federal do Paraná-Campus Curitiba (State Technical University of Paraná), aged between 18 and 28 years with an average of $21 \pm 2.55$ years. This campus has approximately 6,500 students in higher education, out of a pool of 21,000 students in all eleven campuses. To give a perspective of the number of students at the selected university, the University of São Paulo has approximately 88,000 students, the University of Rio de Janeiro has 46,000 students, the State University of Campinas (UNICAMP) has 37,000 students, and the State University of Rio Grande do Sul has 34,000 students. In Brazil, there are approximately six million higher education students, which accounts for $10 \%$ of all students of every educational level nationwide [20].

All of the following tests were performed in STATA 9.2 (StataCcorp, USA) adopting a significance level of 5\% $(p \leq 0,05)$. The results showed a good distribution between men and women, $47.4 \%$ and $52.6 \%$ respectively, and a large concentration of subjects in the second class of socioeconomic status, at $64.5 \%$.

The body mass index (BMI) results were predominantly normal among the participants $(82.1 \%)$, showing an average of $22.4 \pm 3.6 \mathrm{~kg} / \mathrm{m}^{2}$.

Table 1. Poisson regression model - bivariate and multivariate - for data equal or above Physical Activity Level B - basic recommendations for physical activity $(n=300)$

\begin{tabular}{|c|c|c|c|c|c|c|c|c|}
\hline \multirow{2}{*}{ Variables } & \multirow{2}{*}{$n$} & \multirow{2}{*}{$\%$} & \multicolumn{3}{|c|}{ Bivariate Analysis } & \multicolumn{3}{|c|}{ Multivariate Analysis } \\
\hline & & & $\mathrm{RP}$ & $\mathrm{IC}_{95 \%}$ & $p$ & $\mathrm{RP}$ & $\mathrm{IC}_{95 \%}$ & $p$ \\
\hline \multicolumn{9}{|l|}{ BCL } \\
\hline Low & 38 & 37.3 & 1 & - & & 1 & - & \\
\hline Medium & 47 & 44.8 & 1,2 & $(0,78-1,84)$ & 0.434 & 1,18 & $(0,76-1,82)$ & 0.467 \\
\hline High & 81 & 78.6 & 2,11 & $(1,44-3,10)$ & $p=0.011$ & 1,91 & $(1,26-2,90)$ & $p=0.011$ \\
\hline
\end{tabular}

Table 2. Poisson regression model - bivariate and multivariate - for data equal or above Physical Activity Level A complementary recommendations for physical activity $(n=310)$

\begin{tabular}{|c|c|c|c|c|c|c|c|c|}
\hline \multirow{2}{*}{ Variables } & \multirow{2}{*}{$n$} & \multirow{2}{*}{$\%$} & \multicolumn{3}{|c|}{ Bivariate Analysis } & \multicolumn{3}{|c|}{ Multivariate Analysis } \\
\hline & & & $\mathrm{RP}$ & $\mathrm{IC}_{95 \%}$ & $p$ & $\mathrm{RP}$ & $\mathrm{IC}_{95 \%}$ & $p$ \\
\hline \multicolumn{9}{|l|}{ BCL } \\
\hline Low & 56 & 54.9 & 1 & - & & 1 & - & \\
\hline Medium & 80 & 76.2 & 1,39 & $(0,99-1,95)$ & 0.061 & 1,39 & $(0,98-1,96)$ & 0.062 \\
\hline High & 98 & 95.1 & 1,73 & $(1,25-2,41)$ & $p=0.011$ & 1,67 & $(1,17-2,39)$ & $p=0.011$ \\
\hline
\end{tabular}


A bivariate Poisson regression analysis was used to verify the association between the body culture level (BCL) and physical activity level (PAL). Also, a multivariated Poisson regression analysis was used to determine if the mentioned variables had any effect on the analysis between BCL and PAL.

Excluding the high body culture level, the analyses did not find any significant results in the relations between BMI, gender, socioeconomic status (SES) and BCL when associated with PAL.

A strong association was found between PAL and high BCL in both the bivariate and multivariate analyses, as shown in Tables 1 and 2.

\section{Results}

It was demonstrated that $75.5 \%$ of the sample are physically active, $53.5 \%$ with the complementary recommendations of physical activity (PAL A) and only $24.5 \%$ of the population not sufficiently active for the promotion of health (PAL C) [17].

The statistical analysis has shown that there is an association only between a high BCL and PAL. Figure 1 shows the distribution of data among the classes of the BCL and the classes of PAL.

It is possible to perceive that the PAL A group had the highest concentration of high BCL and lowest concentrations of low BCL, while the PAL C group had inverted results.

\section{Discussion}

The main target of this study was achieved successfully. The research shows that $99 \%$ of people who have a high level of body culture also practice enough physical activity to promote health. As the association is only given at a high level, it seems that one must achieve a minimum threshold of relevance to the aspects of body culture to perceive the positive impact of physical activity on his life. After attaining this level of body consciousness, the subject is able to engage in an active lifestyle with more efficiency.

Authors cite that physical activity can be the emanating center of relationships between different areas of life [21]. From this perspective, one can find out the natural role of motricity on human life, changing from a limited conception of an active lifestyle related to fitness and physical conditioning to an expansive meaning of physical activity. Thus, body practices become a path to constructing self-knowledge, where one can develop greater expression, perception, and action within a given society.

The achievement of a high level of body culture has significant relevance to the nine areas addressed in the questionnaire, which demonstrates that physical exercise is important enough to be perceived as an indispensable part of one's well-being. As physical activity has been shown to be associated to the subject's body culture, it is possible to adapt the methods of physical education towards the development of this feature. The enrichment of the individual's body culture should be considered as an important element for the promotion of an active lifestyle in society.

However, there is a necessity to review the aims of current public policies for physical education under the current exclusive biophysical effectiveness of exercise. It should be determined whether or not they cater to the cultural complexity of human motricity.

\section{Conclusions}

This study shows that the common conception of physical activity can be complemented. Body culture is a key factor for the acknowledgement of physical activity as a kinesthetic experience of life. The research

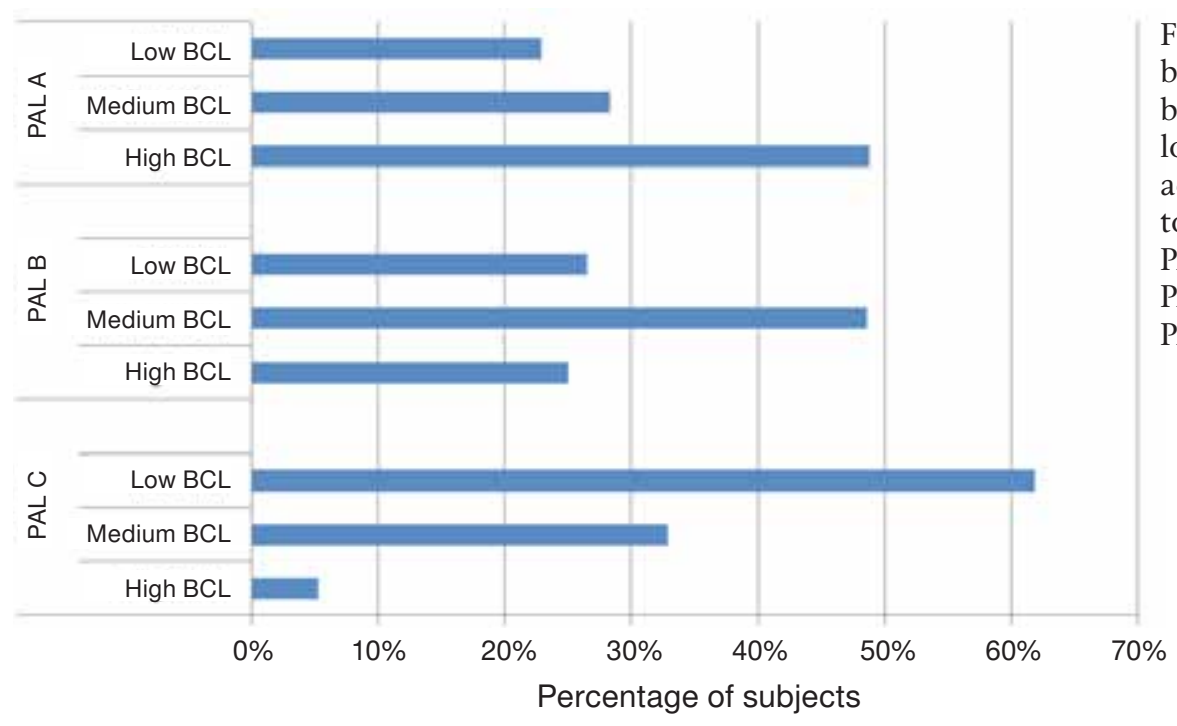

Figure 1. Percentage of subjects distributed by classes of the body culture level (BCL) by strata (high BCL, medium BCL and low BCL) divided by the classes of physical activity level (PAL) of the sample according to the categories established by ACSM (2010): PAL A - complementary recommendation, PAL B - minimum recommendation, PAL C - below the recommended minimum 
results can be taken as an instruction to health and physical education professionals, and may help to develop alternative and innovative strategies for the promotion of a better understanding of the complexity of cultural aspects of physical activity.

Since an increased level of physically active people reflects better on public health, this study should highlight the legitimacy of body culture as content within fitness programs. Other important features of the study were the development of a method to measure body culture level, which can be expanded and improved.

\section{Appendix 1}

\section{Exploratory Questionnaire of Body Culture Concepts - English Version}

\section{Section 1 - Personal}

1 Do you like to practice physical activities?

2 What is the relevance of physical activity in your life?

3 What is the relevance of the emotions/sensations promoted by physical activity in your life?

4 What is the relevance of the practice of physical activity for your cultural development?

5 What is the relevance of the practice of physical activity for the development of your character/personal identity?

6 What is the relevance of the practice of physical activity for your self-esteem?

7 What is the relevance of the practice of physical activity for your expressiveness?

8 What is the relevance of the practice of physical activity for your way of life/personal beliefs/lifestyle?

9 What is the relevance of the practice of physical activity for your self-care/self-knowledge/inner focus?

10 What is the level of satisfaction/pleasure that the practice of physical activity promotes to you?

11 What is the relevance of overcoming challenges in the practice of physical activity?

\section{Section 2 - Health}

12 What is the relevance of the practice of physical activity for your health?

13 What is the relevance of the practice of physical activity for your well-being?

14 What is the relevance of the practice of physical activity for your relaxation?

Section 3 - Social

15 What is the relevance of the practice of physical activity for your socialization/social interaction?

16 What is the relevance of the practice of physical activity as a leisure choice?

\section{Section 4 - Body}

17 What is the relevance of the practice of physical activity in your body appearance/esthetics?

18 What is the relevance of the practice of physical activity in your physical conditioning/physical capacity?

19 Which is the relevance of the practice of physical activity for your level of liveliness in daily routine?

\section{Section 5 - Practice}

20 What is the relevance of the development of body abilities/learning and expanding movement techniques in your practice of physical activity?

21 What is your level of self-effort/discipline on the practice of physical activity?

22 What is your level of interest in new experiences with physical activity?

\section{Section 6 - Cultural}

23 What is your level of interest in sports and other physical activities - inclusively dance - in general media? (Internet, TV, Radio, Journals and Magazines, etc.)

24 What is your level of interest in attending sports events and others physical activity presentations - including dance - such as championships, games, shows, etc.?

25 What is your level of interest in the consumption of products and services related to physical activity?

\section{Section 7 - History}

26 What is the level of your lived experiences with the following activities that were relevant in your life?

26.1 Games and plays

26.2 Rhythmic and expressive activities

26.3 Dances

26.4 Fighting and martial arts

26.5 Team sports

26.6 Individual sports

26.7 Gymnastics and practices of physical conditioning

26.8 Physical activities in nature

26.9 Alternative physical activity

\section{Section 8 - Spaces}

27 What is the relevance of the following areas and equipment for your practice of physical activity?

27.1 Parks and squares

27.2 Nature spaces (beaches, reserves, mountains, etc.)

27.3 Gyms and halls

27.4 Courts, fields and gymnasiums

\section{Section 9 - Physical activity programs}

28 What is the relevance of the presence of a fitness instructor for your practice of physical activity?

29 What is your level of participation in public programs of physical activity?

30 What is your level of participation in public events of physical activity (competitions, meetings, events, etc.)?

31 What is your weekly level of use of public areas/physical activity equipment?

\section{References}

1. World Health Organization, The World Health Report 2008: Primary Health Care Now More Than Ever. World Health Report, 2008. World Health Organization. Geneva, Switzerland, available from: http://www.who.int/ whr/2008/en/ [accessed: February 2010].

2. Steffen L.M., Arnett D.K., Blackburn H., Shah G., Armstrong C., Luepker R.V., Jacobs D.R.Jr, Population trends in leisure-time physical activity: Minnesota Heart Survey, 1980-2000. Med Sci Sports Exerc, 2006, 38 (10), 17161723, doi: 10.1249/01.mss.0000227407.83851.ba.

3. Pitanga F.J.G., Lessa I., Prevalence and variables associated with leisure-time sedentary lifestyle in adults [in 
Portuguese]. Cadernos de Saúde Pública, 2005, 21 (3), 870-877, doi: 10.1590/S0102-311X2005000300021.

4. Carbinatto M., Moreira W.W., Body and health - reconnection of knowledge [in Portuguese]. Revista Brasileira de Ciências do Esporte, 2006, 27 (3), 185-200.

5. Fensterseifer P.E., Corporality and the development of health professionals [in Portuguese]. Revista Brasileira de Ciências do Esporte, 2006, 27 (3), 93-102.

6. Betti M., Physical Education and body culture: a phenomenological perspective and semiotics [in Portuguese]. Revista da Educação Física/UEM, 2007, 18 (2), 207-217.

7. Neira M.G., Identity valorization: popular body culture as a content of the curriculum of Physical Education [in Portuguese]. Revista Motriz, 2007, 13 (3), 174-180.

8. Hannerz U., Cultural complexity: studies in the social organization of meaning. Columbia University Press, New York 1992.

9. Eagleton T., The Idea of Culture [in Portuguese]. UNESP, São Paulo 2005.

10. Elias N., "The Germans". Columbia University Press, New York 1992.

11. Silveira G.C.F., Pinto J.F., Physical education in the perspective of body culture: a pedagogical proposal [in Portuguese]. Revista Brasileira de Ciências e Esporte, 2001, 22 (3), 137-150.

12. Mendes M.I.B.S., Nobrega T.P., Culture movement: reflections on the relationship between body, nature and culture [in Portuguese]. Revista Pensar a Prática, 2009, 12 (2), available from: http://www.revistas.ufg.br/index. php/fef/article/view/6135/4981 [accessed: February 2010].

13. Merleau-Ponty M., Phenomenology of perception [in Portuguese]. Martins Fontes, São Paulo 1994.

14. Tavares A.F., Costa V.L.M., Tubino M.J.G., Recreation sports and its bodily challenges in the German Complex [in Portuguese]. Revista Motriz, 2010, 16 (1), 258-268.
15. IPAQ - International Physical Activity Questionnaire, available from: <http://www.ipaq.ki.se> [accessed July, 2010].

16. Brazilian Association of Research Enterprises, Brazilian Economic Classification Criterion [in Portuguese]. Available from: <www.anep.org.br> [accessed: July 2010].

17. American College Of Sports Medicine "2008 Physical Activity Guidelines for Americans" U.S. Department of Health and Human Services, July, 2010, Available from: $<$ http://www.health.gov/paguidelines/guidelines/default.aspx>. [accessed: February 2010].

18. Likert R., A Technique for the Measurement of Attitudes. Archives of Psychology, 1932, 22 (140), 1-55.

19. Ministry of Health. Resolution $196 / 96$ of the National Health Council - about the regulatory standards and guidelines on research involving humans [in Portuguese]. Diário Oficial da União, October, 1996.

20. Brazilian Institute Of Geography And Statistics. Demographic Census [in Portuguese], November, 2010.

21. Silva A.M., Damiani I.R., The contemporary body practices: assumptions of a field of research and social intervention [in Portuguese]. In: Silva A.M., Damiani I.R., Body Practices v. 3: physical education experiences for human formation [in Portuguese]. Naemblu Ciência e Arte, Florianópolis 2005, 12-39.

Paper received by the Editors: July 7, 2011

Paper accepted for publication: January 4, 2012

Correspondence address

Bruno Barth Pinto Tucunduva

Street: Lodovico Geronazzo. 249

Curitiba, Paraná, Brazil

e-mail: btucunduva@gmail.com 